\title{
Spatial disintegration and arable land security in Egypt: A study of small- and moderate-sized urban areas
}

\author{
Jeffrey S. Robson ${ }^{\mathrm{a}}$, Hany M. Ayad ${ }^{\mathrm{b}}$, Rania Wasfi ${ }^{\mathrm{c}}$, and Ahmed M. El-Geneidy* ${ }^{\mathrm{d}}$
}

${ }^{a}$ Masters Student, School of Urban Planning, McGill University, Montréal, Québec, Canada H3A 2 K6

${ }^{b}$ Associate professor, Architectural Engineering Department, Faculty of Engineering, Alexandria, University, Alexandria, Egypt

${ }^{c} P h D$ Student, Department of Geography, McGill University, Montréal, Québec, Canada H3A 2K6

${ }^{d}$ Assistant professor, School of Urban Planning, McGill University, Montréal, Québec, Canada H3A 2 K6

*Corresponding author

School of Urban Planning

McGill University

Montréal, Québec, Canada H3A 2K6

Telephone: 514-398-8741

Fax: 514-398-8376

e-mail: ahmed.elgeneidy@mcgill.ca

For citation please use: *Robson, J., Ayad, H., *Wasfi, R., \& El-Geneidy, A. (2012). Spatial disintegration and arable land security in Egypt: A study of small- and moderate-sized urban areas. Habitat International. 36(2) 253-260. 


\begin{abstract}
While commonly associated with regional 'mega-cities', rapid urbanization in the less-developed world has also begun to define growth in small- and moderate-sized settlements on the periphery of major metropolitan areas. The dispersal of population growth to these smaller areas holds significant implications for environmental, economic, and social health, and threatens local food security, increases congestions, and induces difficulty in service provision. This study examines the effects of spatial disintegration and rapid urbanization in the stock of arable land in Egypt. To assess this issue, the study will meet three objectives. First, we evaluate the relationship between population growth and urban land cover expansion in small- and moderate-sized settlements in Egypt. Second, we consider the role of selected geographic determinants in influencing the growth of these areas through the use of a regression model. The selection of an appropriate model type is a sub-objective and will be discussed further. Third, these drivers of growth will be assessed through their effects on the country's stock of arable land. These objectives will be met through the development and application of the regression models, in order to examine the relationship between urban land expansion and several independent variables. An increase in population is found to have a positive and statistically significant effect on corresponding urban land cover area. Surprisingly, the variables commonly associated with urbanization in Egypt - proximity to major roads, the capital of Cairo, and the Nile River - though exhibiting a positive relationship with urban growth, are not statistically significant in the selected case studies. This research underlines the necessity for a combined approach to policy formation - with input from policy fields as varied as agriculture, urban planning, and land reclamation - to slow outward growth and maintain arable land stocks.
\end{abstract}

Keywords: arable land; spatial disintegration; urbanization; less-developed world. 


\section{Introduction}

Since the 1970s, rapid urbanization has been an important influence on the physical, social, economic, and environmental development of the global South. The pace of this phenomenon does not appear to be slowing, with much of the future urban growth across the global projected to take place in less-developed regions (Watson, 2009). In general, the process of urbanization is driven by a rise in urban population levels, which in turn compel an increase in urban land cover. However, the population threshold at which urban land expansion occurs is very flexible and is largely dependent on local political and social attitudes to densification and sprawl. In less-developed regions, the process of urbanization often entails the migration of population from rural areas, and the outward expansion of urban areas at the expense of arable land (Lambin, et al., 2001). In turn, the loss of croplands affects both local food and water security, and consequently the ability to support a growing population (Lynch, Binns, \& Olofin, 2001). The concomitant processes of urban population growth and urban land cover expansion can induce stress on urban systems, and can incur difficulties related to infrastructure and service provision, congestion, environmental health and social equity, among other issues (Shatkin, 2007).

This study is concerned with the effect of rapid urbanization and spatial disintegration on the stock of arable land in Egypt. To assess this issue, the study will meet three objectives. First, we evaluate the relationship between population growth and urban land cover expansion (hereafter termed 'land cover growth’) in small- and moderate-sized settlements in Egypt. Second, we consider the role of selected geographic determinants in influencing the growth of these areas through the use of a regression model. The selection of an appropriate model type is a sub-objective and will be further discussed. Third, these drivers of growth will be assessed through their effects on the country's stock of arable land. These objectives will be met through the development and application of the regression models, in order to examine the relationship between urban land expansion and several independent variables. While population is the natural driver of urban growth, it is hypothesized that the selected geographic indicators are equally important in determining the sites of greatest growth and arable land loss.

\section{Spatial disintegration in theory and practice: The example from Egypt}

The most prominent urban growth pattern in the global South is that of 'spatial disintegration'. In his assessment of urban development in Mexico City, Aguilar (1999) uses the term to describe growth that occurs in a metropolitan region, but not in the area's major urban centre. Instead, population and urban land cover growth occur in smaller urban areas on the periphery of the metropolitan region. Alternatively known as 'fragmentation' or 'concentrated deconcentration', this trend has been described in several countries across the global South, including but not limited to: Bahrain (Ben Hamouche, 2004), Chile (Henríquez, Azócar, \& Romero, 2006), Mexico (Aguilar, 1999), and Turkey (Terzi \& Bolen, 2009). 
In the context of this study, the term 'spatial disintegration' will be used to describe the occurrence of this phenomenon hereafter. While the 'mega-cities' of the less-developed world have come to define the popular image of urbanization, these smaller urban settlements have been identified as the force behind urbanization in these areas for the future (Watson, 2009).

As noted previously, the problems associated with spatial disintegration are many. In Egypt, where much of the population growth occurs within the finite space of the Nile river valley and delta, the greatest threat posed by this form of growth is to local food and water security. At the most basic level, rising levels of urbanization associated with spatial disintegration pressures food networks by encroaching on productive agricultural land and reducing crop yields. It stresses this system further by introducing greater numbers of people to the area and by increasing living standard expectations, leading to an escalation in consumption (Hanjra \& Qureshi, 2010). In this way, urbanization can be seen to remove supply while conversely increasing demand. Concerning water security, the expansion of urban areas can degrade local water sources through the introduction of industrial waste and other contaminating agents into the water table (Foster, 2001). In Egypt, where availability of potable water is limited and chiefly supplied by the Nile, wastewater incurred by both domestic and industrial pollution is of great concern (Abdel-Shafy \& Aly, 2007; Wahaab \& Badawy, 2004).

Patterns of urbanization and development in Egypt have largely followed the broader trends experienced throughout the less-developed world. The capital city of Cairo is a very visible example of a regional 'mega-city'; it is the largest metropolitan area in both Egypt and on the African continent in general (Yin, Stewart, Bullard, \& MacLachlan, 2005). From 1947 to 1996, the Cairo metropolitan area's share of the nation's population rose from 12 per cent or 2.2 million people to 17 per cent or 10.2 million people (Sutton \& Fahmi, 2001). While the population of the metropolitan area grew by 8 million inhabitants over fifty years, the carrying capacity of Cairo's urban environment was intended to support only 2 million people for much of that time (El Araby, 2002). The difference between the population level and the available living space in the capital region created a significant demand for outward development, at the expense of surrounding agricultural land. Between 1981 and 1988 alone, the metropolitan area lost 340 square kilometres of arable land to an expanding urban core (El Araby, 2002). While the extent of arable land in the country has since increased, the outward growth of urban land cover on previously agricultural land continues and is occurring at a rate faster than the reclamation efforts conducted by the Egyptian government (Lawrence, Imhoff, Kerle, \& Stutzer, 2002).

Though significant growth has been ongoing in the capital region since the mid-20 ${ }^{\text {th }}$ century, several of Egypt's smaller urban settlements have experienced a more recent wave of population expansion. By 2006, there were 180 urban areas in Egypt with population levels between 15,000 and 200,000 inhabitants, compared to just seven centres with a population greater than 500,000. This suggests 
that Egyptians are now dispersing in greater number to comparatively smaller urban areas. Despite recent trends, initiatives to decentralize growth in Egypt have not always been met with success. In 1969, the Greater Cairo Region Master Scheme called for the control of rapid population growth and urban land cover expansion in the capital (Stewart, Yin, Bullard, \& MacLachlan, 2004). This was to be achieved through the diversion of population away from the city (and its surrounding arable land) to governmentplanned new towns in the Egyptian desert. Though this scheme remained the foundation of the country's urban policy well into the 1980s, the desert new towns failed to attract sizeable populations or to slow continued growth in the capital city (Stewart, et al., 2004). Spatial disintegration would arrive later to the country, as a product of complimentary policy decisions made by the national government in the early 1990s. During this period, the government liberalized the country’s economy, and relaxed its centrallycontrolled housing and spatial planning policies in favour of market-led alternatives (Yin, et al., 2005). Supported by increased investment in the national transportation network and encouraged by this new political-economic climate, private companies were given greater latitude in the purchase and development of rural land adjacent to major conurbations for the purpose of creating suburban communities (El Araby, 2002; Stewart, et al., 2004). This confluence of factors has led to increased urban growth outside the capital city (Denis, 1996). However, in contrast to the earlier decentralization plans advanced by the desert new towns program, contemporary decentralization is occurring on the periphery of major metropolitan areas (Stewart, et al., 2004).

Spatial disintegration in Egypt is a wicked problem. Though outward expansion and suburbanization into the Nile Valley's fertile lands threatens food and water security throughout the country, the alternative practice of a 'smart growth' type of development is equally problematic. The 'smart growth' principle broadly calls for the deployment of infrastructure in key urban areas, closer integration between urban planning and transport policy, green space preservation, and increased densification in central cities (Irwin, Bell, \& Geoghegan, 2003). In Cairo, the capital and Egypt's largest city, is already characterized by a high population density, with 27,000 inhabitants per square kilometre (Wahba \& Zenou, 2005). In this regard, densification does not seem to be an adequate solution. The practice of 'smart growth' principles in Egypt is made more difficult by longstanding attitudes within the country's planning and governance communities. Densification of the central city directly opposes both the 1970s 'desert cities' initiative and the 1990s suburban growth policies advanced at both regional and national levels of government. 


\section{Methodology}

\section{Study area}

The study is focused on a sample of ten small- to moderate-sized urban areas in Egypt. The sample represents approximately five per cent of the country's urban areas with a population of 15,000 or greater. None of the profiled areas have a population greater than 200,000 inhabitants and are comparatively small urban environments when viewed in contrast to the dominant metropolitan centres of Alexandria and Cairo.

The ten cities are selected because they are included within the Government Strategic Urban Planning (SUP) initiative implemented by the Egyptian General Organization for Physical Planning. They are chosen from four Governorates adjacent to the Greater Cairo urban agglomeration. Due to their location from the capital city (Cairo) they exhibit high rates of annual population increase (>3.0\%) and therefore are a good indication of the rural to urban transformation process. Except of Minya el Qamh, the selected cities include at least 20\% of the urban population of their relevant Governorates.

A majority of the sample is characterized by a high population density: the city with the lowest rate - Tamyah - has a population density of 5,430 people per square kilometre, while the city with the highest rate - Ashmoun - has a population density of 31,533 people per square kilometre. For international comparison, the Greater London Area has a population density of 4,900 people per square kilometre, while the most densely populated boroughs of London - Kensington and Chelsea - have population densities of approximately 14,000 people per square kilometre (Office for National Statistics, 2010). Egypt's comparatively high densities must be kept in mind when evaluating the land cover growth trends presented in the study. 


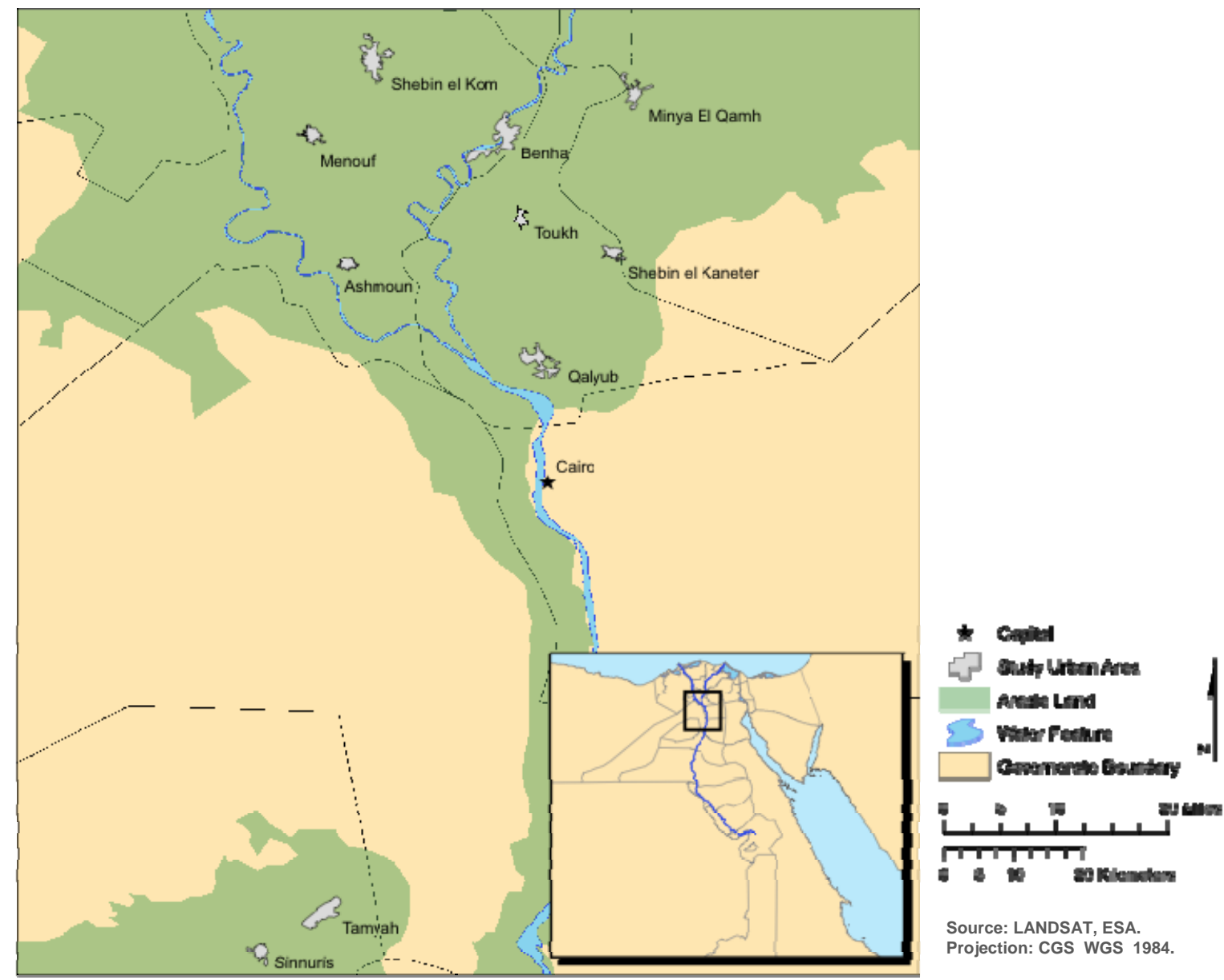

Figure 1. Study Areas in Egypt.

Of the urban areas, eight are clustered within a range of 100 kilometres from Cairo, in the respective governorates (an administrative unit analogous to a state or province) of Monufia, Sharqia, and Qalyubia. The remaining two urban areas are found approximately 70 kilometres southwest of the capital in the governorate of Faiyum. Each of these urban settlements is found within 25 kilometres of the Nile River in a greenbelt centred on the Nile Delta and extending along the Nile Valley. 30,000 square kilometres in total size, the Nile Valley is the country's only major concentration of agriculture land which accounts for approximately 3.5 per cent of its total land area. At first glance, the chosen cities appear clustered in a small geographic area and therefore too uniform to present a diverse sample. However, as much of the country's population is found within close proximity to the Nile River, the sample merely reflects urbanization trends in the country. The urban areas of Ashmoun, Benha, Menouf, Minya el Qamh, Kalyoub, Shebin el Kom, Shebin el Kaneter, and Toukh are each located to the north of Cairo. The towns of Sinnuris and Tamyah are located southwest of Cairo between the Nile River and 
Lake Quarun, adjacent to the city of Faiyum. Additional information concerning each urban area is detailed in Table 1.

\begin{tabular}{llll}
\hline Urban Area & Population (2008) & Area, $\mathbf{~ k m}^{\mathbf{2}} \mathbf{( 2 0 0 8 )}$ & Population per $\mathbf{~ k m}^{\mathbf{2}}$ \\
\hline Ashmoun & 83,931 & 2.66 & 31,533 \\
Benha & 157,701 & 12.25 & 12,869 \\
Menouf & 89,262 & 1.64 & 25,682 \\
Minya el Qamh & 62,331 & 4.69 & 13,303 \\
Kalyoub & 107,303 & 8.63 & 12,421 \\
Shebin el Kanater & 55,272 & 3.19 & 17,310 \\
Shebin el Kom & 177,112 & 10.52 & 16,836 \\
Sinnuris & 82,148 & 3.38 & 24,280 \\
Tamyah & 49,385 & 9.09 & 5,430 \\
Toukh & 62,331 & 2.26 & 27,551 \\
\hline
\end{tabular}

Table 1. Small- and moderate-sized urban areas in Egypt under study. Source: CAPMAS/ESA, 2008.

\section{Data description}

The time-series population data, concerning observations for ten urban areas over four census periods occurring every ten years from 1976 to 2006 (40 observations total), is sourced from the Central Agency for Public Mobilization and Statistics (CAPMAS), the Egyptian national statistics agency in Cairo. Polygon shapefiles were used to develop land cover area measurements (in square kilometres) in a GIS environment, and were originally digitized and error-checked using base maps at a scale of 1:50,000. These were compiled jointly from LANDSAT image repositories provided by the United States Geological Survey (USGS) and survey data provided by the Egyptian Survey Authority (ESA). One notable exception is the Nile Delta and Valley polygon shapefile, which was georeferenced and digitized from a 250m spatial resolution photograph provided by the National Aeronautics and Space Agency's (NASA) Terra/MODIS satellite program. Finally, agricultural data used in the study was drawn from the World Bank’s World Development Indicators for the period of 1975 to 2007.

\section{Process}

To achieve the overall study objectives, we first developed extrapolated population projections for each urban area under review, to use in a population - urban land cover area relationship. In the second stage, two regression models were created to test this relationship. Of these two, the first is an individual exponential growth model, named as such because it uses population and area data segregated according to each urban settlement. The second is a combined spatial model. This model combines all instances of area and population, rather than addressing each settlement individually. The use of the term 'spatial' in the nomenclature is explained by the inclusion of select Egypt-specific geographic determinants of growth in the final predictive model. 
Time-series population and land area data was exported from a GIS environment and input into a regression model. The regression modeling occurred in two stages: first, an exponential projection was generated with time in years as the independent $(\mathrm{x})$ variable and population as the dependent (y) variable. By extrapolating the time-series to the next census period (2016) using the model input, a projected population value was developed. The values developed in the preceding step were then input into a subsequent regression model, with population as the independent variable, and area (in square kilometres) as the dependent variable. The model returned area values for the extrapolated time period based on an exponential trend line developed from the existing dataset. The growth trend was used to demonstrate a basic positive influence of population increase on land cover growth.

\begin{tabular}{lllll}
\hline Variable & Description & Min. & Max. & Std. Dev. \\
\hline Population & Population time series, 1975-2006 & 19671 & 177112 & 38710 \\
Intersect Road & $\begin{array}{l}\text { Footprint intersected or within 5 km of } \\
\text { major road network }\end{array}$ & 0 & 1 & 0 \\
Near Nile & Proximity to Nile (m) & 0 & 31308 & 9839 \\
Near Capital & Proximity to Cairo (m) & 15182 & 76050 & 16194 \\
\hline
\end{tabular}

Table 2. Combined spatial model variables.

With the initial population projection and the individual exponential model completed, the study moved to the second and more nuanced level of analysis. We used a regression model to test the statistical significance of three major Egypt-specific determinants of population growth and land cover expansion, and to develop future urban land cover area values. The variables listed are associated with the proximity of an urban area to various natural or human-generated geographic features. They are: proximity to the capital (in kilometres, due to Cairo's position as the dominant metropolitan area in the region, this was selected as an indicator of 'spatial disintegration'), proximity to the Nile River (in kilometres, as an indicator of availability of arable land), and intersect/near main road (binary value, as an indicator of outward growth likelihood), as noted in Table 2. Distance was calculated from the centre point of each respective urban area using a 'near' proximity function in a GIS environment. The Intersect Road variable was derived using a 5-kilometre buffer to evaluate urban footprint and road overlap. The model was used to test the influence of each of these variables on the development of small- and moderate-sized urban areas under review. Using the random coefficient model described previously, the regression was conducted in Stata software with area as the dependent variable and the geographic data as independent variables at 95 per cent confidence interval. The output area values for both the individual exponential and the combined spatial models were then compared, and subtracted from a total arable land value extrapolated to the future in order to determine the proportion of arable land lost to development. 


\section{Population Modeling Approach \& Assumptions}

The study required the creation of three growth models. The first was concerned with population projections to the next census data (2016) for the areas under review, while the second (individual exponential) and third (combined spatial) was concerned with using the projected population values to determine the effect of this form of growth on urban land cover. To ensure the analysis derived from the models was as accurate as possible, study objectives, data availability, and use was considered. The following section evaluates various population and area modeling techniques with regard to their use in context of the study requirements. We will first look at the applicability of linear, logistic, and exponential regression curves to model the area-population relationship, with respect to their limitations and intended uses.

\section{Linear regression}

While linear regression has been used as an area forecast tool with success by Lopez, Bocco, Mendoza, \& Duhau (2001), their study also relates population growth to area using an exponential curve. While population growth can be linear in form, this is rarely the case over time. The application of such a trend line to an extended time series both underestimates the rate of future growth and disregards the per capita land use changes associated with urbanization. Concerning linear regression as an appropriate model for area growth, we compared observed and predicted area values for the 2006 census year. The results demonstrated that a linear model did not compare favourably to other regression models when calculating for observed values.

\section{Logistic regression}

Logistic regression models exhibit increasing population growth over time until a pre-set ceiling is reached and carrying capacity is achieved. While population growth follows a similar progression to the 's-curve' found in logistic regression, limitations exist that make this model unsuitable for the study. This is seen primarily in the need to set a 'ceiling' level for growth; a requirement that is difficult to satisfy when accounting for multiple urban areas (Wang \& Vom Hofe, 2007). Cheng and Masser (2003) use a spatial logistic regression at a much finer geographic scale compared to the regional scale of this study. Because of the coarser level of analysis and the availability of data used, it becomes more difficult to model the complexities of urban socio-economic systems that are commonly associated with this type of regression. For this reason, it was not used.

\section{Exponential Regression}


The exponential regression growth model uses a constant rate of change for each time period under study (Wang \& Vom Hofe, 2007). Concerning long-term forecasting, the compound effect of this growth rate can lead to anomalies and projection over-estimates. Moreover, the artificial imposition of population limits (for example, family planning policies) can affect the accuracy of this forecast type. While such policies have been introduced in Egypt by the Mubarak government as of 2008, similar strategies have been advanced in the past with little effect (Knickmeyer, 11 June 2008). In their study of Morelia, Mexico, Lopez et al. (2001) use an exponential regression model to closely follow observed population growth patterns over time. Given the advantages of exponential models over relatively small time periods (under 50 years) in comparison to other projection types over the same chronological scale, it was selected to extrapolate population trends over time for the small- and moderate-sized urban areas under review. In an analysis comparing observed and predicted values, the exponential regression model for urban land cover growth returned similar predicted values to those observed for the 2006 census year.

\section{Random intercept and random coefficient models}

The second level of analysis examines the role of select geographic indicators in influencing urban land cover growth. While the preceding models examined the area-population growth relationship at an individual level (that is, one city at a time), this level of analysis adopts a 'combined' approach. Area, population, and indicator data were synthesized into one dataset and were input into two models for testing. The first approach, the random intercept model assumes that the input data for each city under review is found at a different intercept, while the second approach, the random coefficient model posits that input for each city begins at a different intercept and has a different slope. The study tested if the increase in developed land over time was constant or if there was a variance in the increase. A likelihoodratio test, a statistical test used to differentiate between comparable models, was used in order to compare the fit of the two models under review (Hansen, 1992). Applied to the random coefficient model, the test showed that chi-square divided by two (degrees of freedom) was statistically significant, and therefore the random coefficient model is statistically different from the random intercept model. Given that the increase of arable land over time (slope of change) is not a constant increase and is different from one city to the next, the random coefficient model was selected for use.

\section{Results and Discussion}

The individual exponential model (see Table 3), concerning the relationship between population and area (in square kilometres) for each urban area under review, returns significant $p$ values for the majority of areas under study at a minimum of 90 per cent confidence. The only area that does not exhibit statistical significance is Shebin el Kaneter, at 0.173. In contrast, the towns of Shebin el Kom and Minya 
el Qamh exhibit high statistical significance, at 0.004 and 0.009 respectively. Urban areas with high statistical significance also display high R square values, with a mean value of 0.904 . A notable outlier is again found in Shebin el Kaneter, with an R square value of 0.737 , compared to a high value of 0.993 shown by Shebin el Kom. In general, eight of ten models generated in the process are considered to possess a reasonable goodness-of-fit to the practical data they are representing. Observed and predicted population values for the study areas are found in Table 4. Though the general relationship shown in this model is an important first step, geographic indicators will also be considered to provide greater Egyptspecific contextualization.

\begin{tabular}{lllll}
\hline Urban Area & Constant & B1 & R Square & Significance \\
\hline Ashmoun & 0.874 & $1.44 \mathrm{E}-05$ & 0.813 & $0.098^{*}$ \\
Benha & 2.314 & $1.04 \mathrm{E}-05$ & 0.936 & $0.032^{* *}$ \\
el Kanater & 0.170 & $5.74 \mathrm{E}-05$ & 0.737 & 0.173 \\
el Kom & 2.467 & $8.25 \mathrm{E}-06$ & 0.993 & $0.004^{* * *}$ \\
el Qamh & 0.910 & $2.56 \mathrm{E}-05$ & 0.983 & $0.009^{* * *}$ \\
Kalyoub & 0.863 & $2.16 \mathrm{E}-05$ & 0.976 & $0.012^{* *}$ \\
Menouf & 0.521 & $2.25 \mathrm{E}-05$ & 0.886 & $0.059^{*}$ \\
Sinnuris & 0.487 & $2.49 \mathrm{E}-05$ & 0.877 & $0.064^{*}$ \\
Tamyah & 4.160 & $1.71 \mathrm{E}-05$ & 0.876 & $0.014^{*}$ \\
Toukh & 0.396 & $2.89 \mathrm{E}-05$ & 0.971 & \\
\hline$* *$ significant at 99\% confidence level & & & \\
$* *$ significant at 95\% confidence level & & & \\
$* \quad$ significant at 90\% confidence level & & &
\end{tabular}

Table 3. Individual exponential model output. 


\begin{tabular}{llllllll}
\hline & $\mathbf{1 9 7 6}$ & $\mathbf{1 9 8 6}$ & $\mathbf{1 9 9 6}$ & $\mathbf{2 0 0 6}$ & $\begin{array}{l}\mathbf{2 0 1 6} \\
\text { projected }\end{array}$ & $\begin{array}{l}\text { \% Change, } \\
\mathbf{2 0 0 6 - 2 0 1 6}\end{array}$ & $\begin{array}{l}\text { \% Change, } \\
\mathbf{1 9 7 6 - 2 0 1 6}\end{array}$ \\
\hline Ashmoun & 39,507 & 54,450 & 68,793 & 83,931 & 106,482 & 26.87 & 169.53 \\
Benha & 88,845 & 115,701 & 145,800 & 157,701 & 196,278 & 24.46 & 120.92 \\
el Kaneter & 25,505 & 35,659 & 48,372 & 55,272 & 73,255 & 32.54 & 187.22 \\
el Kom & 102,805 & 132,209 & 156,794 & 177,112 & 212,535 & 20.00 & 106.74 \\
el Qamh & 32,609 & 46,222 & 55,600 & 62,331 & 78,521 & 25.97 & 140.80 \\
Kalyoub & 62,564 & 84,413 & 97,186 & 107,303 & 129,734 & 20.90 & 107.36 \\
Menouf & 55,208 & 69,673 & 77,773 & 89,262 & 103,140 & 15.55 & 86.82 \\
Sinnuris & 42,010 & 55,187 & 68,442 & 82,148 & 101,303 & 23.32 & 141.14 \\
Tamyah & 19,671 & 29,238 & 38,383 & 49,385 & 65,709 & 33.05 & 234.04 \\
Toukh & 32,609 & 46,222 & 55,600 & 62,331 & 78,521 & 25.97 & 140.80 \\
\hline
\end{tabular}

Table 4. Population change over time, 1976-2016 (projected).

The combined spatial model ostensibly provides a more nuanced perspective on urban growth processes in Egypt. Though the individual exponential models assessed the relationship between population and area, they did so in purely theoretical conditions and without considering cause-effect mechanisms. Indeed, no specific geographic influences were included, nor were the time-series values of population and area for each urban area aggregated into one dataset. In contrast, the combined spatial model includes the general population and area values used in the creation of the individual models, but also includes three independent variables that have been described in the literature as important influences on urbanization and growth. Though these influences have been described as important indicators of growth, their statistical significance suggests otherwise. The output of the combined spatial model is reported in Table 5.

\begin{tabular}{lll}
\hline Variable & Coefficient & Significance \\
\hline Population & 6.497587 & $0.035^{* *}$ \\
Intersect Road & 76033.54 & 0.948 \\
Near Nile & -78.68967 & 0.334 \\
Near Capital & 0.0006062 & 0.239 \\
Constant & 1746485 & 0.17 \\
\hline$* *$ Significant at 95\% confidence level & \\
\hline
\end{tabular}

Table 5. Combined spatial model output.

In the combined spatial model, population remains the most important driver of urban growth, with statistical significance of 0.035 . For each individual increase in population in any of the Egyptian urban areas under study, land cover increases by 6.49 metres squared. Contrary to the study hypothesis and to the prominent role afforded to the geographic variables in the literature, the statistical significance for each is low. The location of an urban area near or intersected by a major road network exhibits 0.948 statistical significance, while proximity to the Nile River and proximity to the capital metropolitan area show significance of 0.334 and 0.239 , respectively. In each case, they are under the minimal acceptable confidence level of 95.0 per cent. The model otherwise demonstrates that the location of an urban area 
near the Nile River has an inverse relationship with the increase in arable land, and that proximity to a major road network or the capital metropolitan area exhibits a positive relationship.

\begin{tabular}{llll}
\hline Urban Area & Observed & Individual Exponential & Combined Spatial* \\
\hline Ashmoun & 2.66 & 2.93 & 6.75 \\
Benha & 12.25 & 11.98 & 7.82 \\
el Kanater & 3.19 & 4.13 & 4.95 \\
el Kom & 10.52 & 10.63 & 7.70 \\
el Qamh & 4.69 & 4.47 & 7.06 \\
Kalyoub & 8.64 & 8.72 & 6.14 \\
Menouf & 3.48 & 3.87 & 7.35 \\
Sinnuris & 3.38 & 3.75 & 6.96 \\
Tamyah & 9.09 & 9.69 & 6.47 \\
Toukh & 2.26 & 2.39 & 6.15 \\
Total & $\mathbf{6 0 . 1 7}$ & $\mathbf{6 2 . 5 8}$ & $\mathbf{6 7 . 3 5}$ \\
\hline Percentage of Observed & 100.00 & 104.00 & 111.94 \\
\hline *Combined weighted model has been adjusted to exclude 2006 coefficient value.
\end{tabular}

Table 6. Observed and predicted area (square kilometres) of urban land cover, 2006.

In Table 6, we compare actual and predicted values for 2006 (the last census year with a recorded population and area). In doing so, many similarities and differences can be observed. The individual exponential model, in assessing only one urban area at a time, more accurately follows actual individual urban population values for 2006. The highest difference between predicted and actual values is observed in Shebin el Kaneter, with a difference of 0.93 square kilometres. However, the average difference between individual exponential predicted and actual values is only 0.33 square kilometres. In total, the predicted values assume 104 per cent of the actual total. The combined spatial model displays greater variation among area values from the actual instances. Where the individual exponential model overestimates area values in all but two cases, the combined spatial model overestimates some values (five in total), while underestimating for others. This is due to differences in the data included in the construction of each model type. The individual exponential models only includes values for one urban area at a time (and is thus characterized by different coefficients from city to city), while the combined model uses aggregated data covering all 40 (ten cities by four time periods) instances. Because of this greater variation, the average difference between actual and predicted values increases to 3.19 square kilometres. In total, the predicted value total exceeds that of the actual, at nearly 112 per cent. 


\begin{tabular}{lll}
\hline Urban Area & Individual Exponential & Combined Spatial \\
\hline Ashmoun & 4.05 & 9.84 \\
Benha & 17.91 & 11.01 \\
el Kanater & 11.60 & 8.00 \\
el Kom & 14.24 & 10.87 \\
el Qamh & 6.77 & 10.10 \\
Kalyoub & 14.15 & 9.23 \\
Menouf & 5.20 & 10.38 \\
Sinnuris & 6.04 & 10.02 \\
Tamyah & 12.82 & 9.52 \\
Toukh & 3.82 & 9.20 \\
\hline Total & $\mathbf{9 6 . 6 8}$ & $\mathbf{9 8 . 1 6}$ \\
\hline
\end{tabular}

Table 7. Predicted area (square kilometres) of urban land cover, 2016.

While the individual exponential model appears to better reflect growth in the urban areas under study using observed 2006 values as a benchmark (refer to Table 6), extrapolation of both models to the future exhibits something different altogether. Using population projections for each area to 2016 as an input, contemporary area totals show a leveling-off, as seen in Table 7. Sizeable variation remains between the individual urban values for the single and combined models, with a minimum difference between comparable areas of 1.48 square kilometres and a maximum of 6.9, with a differential average of 4.28. However, despite these apparent differences the tendency of the individual model to overestimate and the combined model to both over- and underestimate at times leads to a balanced result. The total land area projected by the individual exponential model is 96.68 square kilometres, compared to a combined spatial model value of 98.16 square kilometres. Where a seven per cent difference existed between the models for the year 2006, the year 2016 values only show an approximate one and a half per cent difference between each other.

\begin{tabular}{lll}
\hline Urban Area & Using Single & Using Combined \\
\hline Ashmoun & $0.013 \%$ & $0.031 \%$ \\
Benha & $0.057 \%$ & $0.035 \%$ \\
el Kanater & $0.037 \%$ & $0.025 \%$ \\
el Kom & $0.045 \%$ & $0.034 \%$ \\
el Qamh & $0.021 \%$ & $0.032 \%$ \\
Kalyoub & $0.045 \%$ & $0.029 \%$ \\
Menouf & $0.017 \%$ & $0.033 \%$ \\
Sinnuris & $0.019 \%$ & $0.032 \%$ \\
Tamyah & $0.041 \%$ & $0.030 \%$ \\
Toukh & $0.012 \%$ & $0.029 \%$ \\
\hline Total & $\mathbf{0 . 3 0 6 \%}$ & $\mathbf{0 . 3 1 1 \%}$ \\
\hline
\end{tabular}

Table 8. Percentage of arable land assumed by urban land cover, 2016.

In Table 8, we applied the total area footprint and projected future expansion to arable land levels (total 31,549 square kilometres). The generated numbers appear underwhelming at first sight, considering 
the stated gravity of the problem. The total arable land stock lost to urban expansion according to the individual exponential model is 0.30 per cent, or less than one percentage point. The combined spatial model incurs a similar loss of 0.31 per cent per cent. The individual model exhibits greater overall variation in the percentage of arable land stock lost to urban land cover expansion, with a minimum value of 0.012 per cent and a maximum of 0.057 per cent. The combined model displays less variation, with a minimum value of 0.025 per cent ad a maximum value of 0.035 per cent of arable land assumed by urban land cover including expansion. However, between the two models, the average percentage of arable land covered by urban areas is equal, at 0.031 per cent.

Though the percentage of arable land lost to urban encroachment in Egypt appears minor regardless of the simulation model chosen, the sample size of this study must be considered. The sample is small relative to the number of urban areas in the country. Of the 201 notable urban areas in Egypt, 178 of them have a population of 180,000 or less, including the ten sample areas. With the small percentage of areas under study, we must also consider that similar processes of spatial disintegration and urbanization are most certainly at work in other urban areas of similar size throughout the country. Because of this, the concerns presented here become more pivotal. Moreover, as land cover growth is a function of population size, the larger populations found in the upper threshold cities that go largely unrepresented in this study would create a more measurable and negative impact on arable land percentages.

\section{Conclusions and Recommendations}

There is no doubt that the processes of urbanization occurring throughout the global South are placing new pressures on surrounding (and often precarious) stocks of arable land. Using two types of statistical models, this study has demonstrated at a macro-level the effect of land cover growth on arable land stock in Egypt using a number of variables. Expectedly, it is found that population level is the largest determinant of land cover growth. The high-density form of the study areas notwithstanding, increasing population levels drive outward land cover expansion. However, it is the tendency towards high-density living that mitigates overall expansion rates; areas with a history of sprawl would potential reflect higher rates. Contrary to the established literature on the subject of urbanization in the global South, the secondary geographic indicators (proximity to main road networks, proximity to the capital area, and proximity to the Nile) were not found to be statistically significant, and consequently hold less influence on the growth of urban land cover in the areas under study. However, it should be noted that the small sample size used in the study may be a factor here. Though the influence of population growth on arable land stock when using either simulation model type is negligible, the final percentages must be placed in a context of the relatively small initial sizes of the study's urban areas relative to overall land stock. 
While the study has taken an important first step in providing a cumulative assessment of urban land cover growth in the developing world, several recommendations have been identified as relevant for future research design and discussion. As noted previously, the study would benefit from a larger sample size. By drawing more data from a field of 201 entries, the study could provide a greater picture of urbanization and spatial disintegration in the country, while also allowing for a more comprehensive assessment of their effects on arable land stock. Indeed, the returned arable land percentages in this study represent only a small section of available land in Egypt. In a similar vein, using a greater time series could better allow the study to track changing rates of population and area over time. In using data from the mid-1970s to present, the study only tracks urban growth over a period of increasing urbanization in the country. While sufficient for the purposes of this study, the inclusion of more data would provide greater context in the construction of statistical models. For future study, it is also important to examine the role of geographic determinants of growth, given their failure to impact this study in a significant way. While selected due to the importance placed on them in the existing literature and their comparative ease of objective evaluation, it appears that other less measurable factors may be more worthy of inclusion. Socio-economic and political factors, though more difficult to quantify in both statistical and spatial modeling environments, may be worthwhile for inclusion as alternative indicators of growth (Xiao, et al., 2006). These influences are wide-ranging and include a variety of policies and attitudes not limited to: economic and industrial development, urban planning, transportation, family planning and demographics, and governance.

Through this study, it is clear than an interdependency of policy responses is required to address arable land loss. The negative influence of rapid urbanization and physical expansion on local food security cannot be mitigated through action made by only one group of policymakers, be they involved in setting agricultural or urban policy. Without assistance from other fields of policy and indeed, from each other, the policy responses form part of an incomplete puzzle. The densification initiatives and 'smart growth' planning controls - the use of being a typical response to rapid urban growth - become effective only in slowing chaotic growth, rather than mitigating the associated negative externalities. Similarly, agricultural and environmental policies - be they aimed at encouraging small-scale food production or conserving rural lands - require the de facto consent of regional and municipal levels of government to be effective.

Ultimately, to preserve arable land for agriculture and other related physical support systems, urban policymakers must enter into a symbiotic relationship with actors involved in policy sections as disparate as transportation, food, water conservation, and housing. While bureaucratic divisions are in part responsible for the problem described above, they can also be harnessed to develop a solution. While impractical to advocate the consolidation of these policy groups to meet the challenges to arable land - 
each group serving a vital function on their own accord - a potential solution rests in the formation of an interdisciplinary committee with representatives drawn from each relevant field. By encouraging greater discussion with individuals outside one’s own specialization, new interdisciplinary approaches and solutions can be developed. While the preceding government's approach of integrating environmental policy into broader national policies suggests a degree of congruence, the events of Spring 2011 and the resulting uncertainty in the country make it unclear whether this approach will be maintained (Zetter \& Hassan, 2002).

Attempts to overcome the problems detailed in this study are not just constrained by a lack of interdisciplinary dialogue between policy circles. A failure to coordinate between different levels and geographies of governance is also a hurdle to be overcome. Indeed, central government ministries and their respective policy circles are not the only groups to be called to work together. While it is clear that different levels of government - from local agencies to the central government - must cooperate, the spread of the Nile delta across several regions also suggests that an element of lateral, or interregional, cooperation is also necessary. In the Egyptian context, the attainment of cooperation between groups appears difficult. The history of planning policy development in the country is characterized by poor coordination and conflict between agencies, weak institutional capacity, uncertain jurisdictional boundaries, and the occasional overriding presidential decree (Zetter \& Hassan, 2002). While it is again important to note that the events of Spring 2011 have altered the context of governance in the country, it is again yet unclear what implications this transformative process will have on governmental congruence.

\section{Acknowledgements}

We would like to acknowledge Julien Surprenant-Legault for his assistance with the literature review. Also we would like to thank to the anonymous reviewers for their feedback and comments.

\section{List of References}

Abdel-Shafy, H., \& Aly, R. (2007). Wastewater Management in Egypt. In M. Zaidi (Ed.), Wastewater Reuse-Risk Assessment, Decision-Making and Environmental Security (Vol. 27, pp. 375-382): Springer Netherlands.

Aguilar, A. G. (1999). Mexico City growth and regional dispersal: The expansion of largest cities and new spatial forms. Habitat International, 23(3), 391-412.

Ben Hamouche, M. (2004). The changing morphology of the gulf cities in the age of globalisation: the case of Bahrain. Habitat International, 28(4), 521-540.

Cheng, H. Q., \& Masser, I. (2003). Urban growth pattern modeling: a case study of Wuhan city, PR China. Landscape and Urban Planning, 62(4), 199-217.

Denis, E. (1996). Urban Planning and Growth in Cairo. Middle East Report(202), 7-12.

El Araby, M. (2002). Urban growth and environmental degradation - The case of Cairo, Egypt. Cities, 19(6), 389-400. 
Foster, S. S. D. (2001). The interdependence of groundwater and urbanisation in rapidly developing cities. [doi: DOI: 10.1016/S1462-0758(01)00043-7]. Urban Water, 3(3), 185-192.

Hanjra, M. A., \& Qureshi, M. E. (2010). Global water crisis and future food security in an era of climate change. [doi: DOI: 10.1016/j.foodpol.2010.05.006]. Food Policy, In Press, Corrected Proof.

Hansen, B. E. (1992). The likelihood ratio test under nonstandard conditions: Testing the markov switching model of gnp. Journal of Applied Econometrics, 7(S1), S61-S82.

Henríquez, C., Azócar, G., \& Romero, H. (2006). Monitoring and modeling the urban growth of two midsized Chilean cities. Habitat International, 30(4), 945-964.

Irwin, E. G., Bell, K. P., \& Geoghegan, J. (2003). Modeling and managing urban growth at the ruralurban fringe: A parcel-level model of residential land use change. Agricultural and Resource Economics Review, 32(1), 83-102.

Knickmeyer, E. (11 June 2008). Egypt's President Urges Family Planning; Campaign Launched Amid Economic Difficulties, Unrest Over Food Prices. Washington Post, p. A10. Retrieved from http://www.washingtonpost.com/wp-dyn/content/story/2008/06/10/ST2008061002696.html

Lambin, E. F., Turner, B. L., Geist, H. J., Agbola, S. B., Angelsen, A., Bruce, J. W., et al. (2001). The causes of land-use and land-cover change: moving beyond the myths. [doi: DOI: 10.1016/S09593780(01)00007-3]. Global Environmental Change, 11(4), 261-269.

Lawrence, W. T., Imhoff, M. L., Kerle, N., \& Stutzer, D. (2002). Quantifying urban land use and impact on soils in Egypt using diurnal satellite imagery of the Earth surface. International Journal of Remote Sensing, 23(19), 3921-3937.

Lopez, E., Bocco, G., Mendoza, M., \& Duhau, E. (2001). Predicting land-cover and land-use change in the urban fringe - A case in Morelia city, Mexico. Landscape and Urban Planning, 55(4), 271285.

Lynch, K., Binns, T., \& Olofin, E. (2001). Urban agriculture under threat: The land security question in Kano, Nigeria. [doi: DOI: 10.1016/S0264-2751(01)00008-7]. Cities, 18(3), 159-171.

Office for National Statistics. (2010). London: population and migration. Office for National Statistics Regional Profiles Retrieved 10 September, 2010, from http://www.statistics.gov.uk/cci/nugget.asp?id=2235

Shatkin, G. (2007). Global cities of the South: Emerging perspectives on growth and inequality. [doi: DOI: 10.1016/j.cities.2006.10.002]. Cities, 24(1), 1-15.

Stewart, D. J., Yin, Z. Y., Bullard, S. M., \& MacLachlan, J. T. (2004). Assessing the spatial structure of urban and population growth in the Greater Cairo area, Egypt: A GIS and imagery analysis approach. Urban Studies, 41(1), 95-116.

Sutton, K., \& Fahmi, W. (2001). Cairo's urban growth and strategic master plans in the light of Egypt's 1996 population census results. Cities, 18(3), 135-149.

Terzi, F., \& Bolen, F. (2009). Urban Sprawl Measurement of Istanbul. European Planning Studies, 17(10), 1559-1570.

Wahaab, R. A., \& Badawy, M. I. (2004). Water quality assessment of the River Nile system: an overview. Biomed Environ Sci, 17(1), 87-100.

Wahba, J., \& Zenou, Y. (2005). Density, social networks and job search methods: Theory and application to Egypt. [doi: DOI: 10.1016/j.jdeveco.2004.11.006]. Journal of Development Economics, 78(2), 443-473.

Wang, X., \& Vom Hofe, R. A. (2007). Research methods in urban and regional planning. Beijing

New York: Tsinghua University Press; Springer.

Watson, V. (2009). 'The planned city sweeps the poor away ... ': Urban planning and 21st century urbanisation. Progress in Planning, 72, 151-193.

Xiao, J., Shen, Y., Ge, J., Tateishi, R., Tang, C., Liang, Y., et al. (2006). Evaluating urban expansion and land use change in Shijiazhuang, China, by using GIS and remote sensing. [doi: DOI: 10.1016/j.landurbplan.2004.12.005]. Landscape and Urban Planning, 75(1-2), 69-80.

Yin, Z.-Y., Stewart, D. J., Bullard, S., \& MacLachlan, J. T. (2005). Changes in urban built-up surface and population distribution patterns during 1986-1999: A case study of Cairo, Egypt. [doi: DOI: 
10.1016/j.compenvurbsys.2005.01.008]. Computers, Environment and Urban Systems, 29(5), 595-616.

Zetter, R., \& Hassan, A.-M. (2002). Urban economy or environmental policy? The case of Egypt. Journal of Environmental Policy \& Planning, 4(2), 169-184. 